\title{
LETTERS
}

\section{Guideline groups should not make recommendations when there is considerable uncertainty}

This CMAJ commentary is all about how physicians should respond to uncertainty, ${ }^{1}$ and I strongly disagree with the approach advocated by Drs. Neumann and Schünemann. They point to evidence that physicians are uncomfortable with uncertainty and wish someone would just tell them what to do. Fair enough, but uncertainty will not go away just because we do not like it. Graded recommendations based on the strength of available evidence and the size of benefit are what physicians need from guidelines. When enough uncertainty exists where no one really knows what to do, then physicians should admit that.

It is easily plausible that guideline recommendations based on expert opinion alone could standardize care without providing any benefit. They could also make it harder to obtain evidence. If surgery $X$ is the standard of care, despite very poor quality evidence, then it will be harder to convince ethics boards that it is reasonable to withhold surgery $X$ from a control group. Physicians already struggle with the concept that guidelines contain recommendations based on both strong and weak evidence. Do not cause more confusion by adding more consensus-based recommendations.

When the evidence is strong, we should use it to standardize practice; when it is very weak, there is no benefit to standardization. If physicians want suggestions on what to do in the face of uncertainty then they can look to narrative reviews. Uncertainty is part of life and pretending otherwise is not healthy for the medical community.

\section{Roger Suss MD}

Family physician, University of Manitoba, Winnipeg, Man.

Cite as: CMAJ 2020 July 6;192:E783. doi: 10.1503/cmaj.75271

\section{Reference}

1. Neumann I, Schünemann HJ. Guideline groups should make recommendations even if the evidence is considered insufficient. CMAJ 2020;192: E23-4.

Competing interests: None declared. 